Marquette University

e-Publications@Marquette

Psychology Faculty Research and Publications

Psychology Department

$10-1-2015$

\title{
A Review of Peer Relationships and Friendships in Youth With ADHD
}

Denise M. Gardner

Marquette University, denise.gardner@marquette.edu

Alyson C. Gerdes

Marquette University, alyson.gerdes@marquette.edu

Accepted version. Journal of Attention Disorders, Vol. 19, No. 10 (October 2015): 844-855. DOI. (C) 2015 SAGE Publications. Used with permission. 


\title{
A Review of Peer Relationships and Friendships in Youth with ADHD
}

\author{
Denise M. Gardner \\ Marquette University, \\ Milwaukee, WI \\ Alyson C. Gerdes \\ Department Psychology, Marquette University \\ Milwaukee, WI
}

\begin{abstract}
Objective: The purpose of this essay is to examine peer relationships in youth with ADHD and to review current peer functioning interventions. Method: The studies included in this review were identified using the following search terms: "attention-deficit/hyperactivity disorder," "ADHD," "peer relationships," "friendships," "social skills," "intervention," and "treatment." Other than a few seminal studies published prior to 2000, studies included were published between 2000 and 2012.

Results/Discussion: Background information regarding peer relationship difficulties and specific social skills deficits of youth with ADHD is reviewed and current social skills and friendship intervention programs are examined. Future directions also are provided.

Keywords ADHD, youth, peer relationships
\end{abstract}

Journal of Attention Disorders, Vol 19, No. 10 (October 2015): pg. 844-855. DOI. This article is @ SAGE Publications and permission has been granted for this version to appear in e-Publications@Marquette. SAGE Publications does not grant permission for this article to be further copied/distributed or hosted elsewhere without the express permission from SAGE Publications. 
NOT THE PUBLISHED VERSION; this is the author's final, peer-reviewed manuscript. The published version may be accessed by following the link in the citation at the bottom of the page.

ADHD is a common childhood disorder affecting between $3 \%$ and $7 \%$ of school-age children (Diagnostic and Statistical Manual of Mental Disorders, 4th ed., text rev. [DSM-IV-TR]; American Psychiatric Association [APA], 2000). Therefore, children with ADHD are likely to be present in nearly every classroom in the United States (Hoza, 2007; McQuade \& Hoza, 2008). To meet criteria for one of the three ADHD subtypes, children must exhibit at least six symptoms of inattention and/or hyperactivity/impulsivity in two or more settings, as rated by parents and teachers (APA, 2000). In addition, the symptoms of inattention and/or hyperactivity/impulsivity must cause significant impairment in academic, socioemotional, and/or familial functioning (APA, 2000). Research has demonstrated that children with ADHD often continue to meet diagnostic criteria and experience academic and social impairment in adolescence (Barkley, Fischer, Edelbrock, \& Smallish, 1990; Hurtig et al., 2007).

In fact, peer difficulties represent a significant area of impairment for children and adolescents with ADHD (Hoza, 2007). Peer difficulties may include peer stigmatization, neglect, rejection, and victimization. More specifically, children with ADHD tend to have fewer friends and lower quality friendships, and experience greater peer victimization than typically developing children (Hoza, 2007). Peer relationship difficulties in childhood and adolescence are predictive of future negative outcomes, including substance abuse, academic difficulties, psychopathology, and continued social difficulties (Bagwell, Newcomb, \& Bukowski, 1998; Hoza, 2007).

While effective interventions for behavior management in home and classroom contexts are well established, effective peer functioning interventions require additional investigation. Up to this point, peer functioning interventions have typically been implemented as part of larger behaviorally focused interventions that also include behavior modification and parent training, with few programs focusing solely and intensively on dyadic friendship building (Hoza, 2007; MTA Cooperative Group, 1999). Recently, researchers have highlighted the need for long-term interventions that directly address peer relationship difficulties with an emphasis on dyadic peer relationships, rather than peer group acceptance (Hoza, 2007; Mikami, 2010; Normand et al., 2011). Friendship-building programs, which target dyadic peer relationships, have demonstrated positive outcomes for several permission has been granted for this version to appear in e-Publications@Marquette. SAGE Publications does not grant permission for this article to be further copied/distributed or hosted elsewhere without the express permission from SAGE Publications. 
populations with peer functioning difficulties, including children with ADHD and adolescents with autism spectrum disorders (ASDs) and fetal alcohol syndrome (Frankel \& Myatt, 2007; Frankel, Myatt, Cantwell, \& Feinberg, 1997; Frankel \& Whitham, 2011; Laugeson, Frankel, Mogil, \& Dillon, 2009).

Due to the significance of peer relationship difficulties for youth with ADHD and their impact on functioning in multiple domains, it is important to examine current research and clinical practices related to peer functioning interventions to investigate possible future directions for the area of the field. Thus, the purpose of this review is to examine peer relationships and friendships in youth diagnosed with ADHD and to summarize the current interventions available to improve peer functioning. The studies included in this review were identified using the following search terms: "attention-deficit/hyperactivity disorder," "ADHD," "peer relationships," "friendships," "social skills," "intervention," and "treatment." Other than a few seminal studies published prior to 2000, studies included were published between 2000 and 2012.

\section{Peer Relationship Difficulties Related to ADHD}

According to the literature, between $50 \%$ and $70 \%$ of children with ADHD experience peer relationship difficulties, which highlights the significance of social impairment for this population (see Antshel, Macias \& Barkley, 2009 for review). In addition, peer difficulties in children with ADHD are often deep-rooted by age 7 and are almost immediately evident in new social situations (Hoza, 2007). Peer relationship difficulties and negative peer reputations often continue into adolescence and remain a significant source of impairment identified by parents and teachers (Bagwell, Molina, Pelham, \& Hoza, 2001; Mrug et al., 2012; Sibley, Evans, \& Serpell, 2010).

Children and adolescents with ADHD are more likely to engage in inappropriate and impulsive behaviors than their typically developing peers (Mrug, Hoza, \& Gerdes, 2001). These negative behaviors are more likely to occur in unstructured and unsupervised situations, such as during play, and typically lead to impaired peer relationships (Cordier, Bundy, Hocking, \& Einfeld, 2010). In addition, a study conducted by Heiman (2005) found that children with ADHD permission has been granted for this version to appear in e-Publications@Marquette. SAGE Publications does not grant permission for this article to be further copied/distributed or hosted elsewhere without the express permission from SAGE Publications. 
tend to define friendship differently than typically developing children. Specifically, children with ADHD reported that a best friend is someone who is "fun" and "mutually entertaining," whereas typically developing children described a best friend as someone who provides emotional support and "a sense of security" (Heiman, 2005). Thus, children with ADHD tend to value certain characteristics in friendships, which may conflict with those valued by their peer group and lead to decreased likelihood of developing mutually satisfying friendships.

Research also suggests that between $56 \%$ and $76 \%$ of children with ADHD have no mutual friendships, compared with $10 \%$ to $32 \%$ of typically developing children (see Hoza, 2007, for reviews).

Furthermore, the peer relationships and friendships of children with ADHD tend to be characterized by fewer positive features, more negative features, and less stability than those of typically developing peers (Blachman \& Hinshaw, 2002; Hoza, Mrug, et al., 2005; Normand et al., 2011). Specifically, Blachman and Hinshaw (2002) found that girls with ADHD reported fewer friendships than typically developing girls. In addition, girls with ADHD were more likely to report lower quality friendships and greater conflict and relational aggression in existing friendships (Blachman \& Hinshaw, 2002).

This may partially be due to the fact that children hold negative attributions about peers with ADHD (Swords, Heary, \& Hennessy, 2011; Walker, Coleman, Lee, Squire, \& Friesen, 2008). Walker and colleagues (2008) conducted a large-scale national survey to assess children's perceptions of peers with depression, ADHD, and asthma. The results of the study indicated that on average, children hold more negative attributions (e.g. "gets in trouble more often" and "is more violent") and fewer positive attributions (e.g. "is smarter") for peers with ADHD than for peers with asthma or depression (Walker et al., 2008). In addition, Swords and colleagues (2011) examined the variables that predict peer acceptance of children with ADHD. The results of the study indicated that perceived responsibility for one's behavior was the most important predictor of peer acceptance for male children with ADHD (Swords et al., 2011). More specifically, increased belief in the child's responsibility for his behavior was associated with decreased acceptance (Swords et al., 2011). Thus, the combination of poor social reputations and negative attributions among peers is likely related to peer neglect and rejection. permission has been granted for this version to appear in e-Publications@Marquette. SAGE Publications does not grant permission for this article to be further copied/distributed or hosted elsewhere without the express permission from SAGE Publications. 
Children with ADHD tend to experience greater peer neglect and rejection than their typically developing peers (Hoza, 2007; Hoza, Mrug, et al., 2005). Researchers have distinguished between neglect, or being ignored by peers and socially isolated, and active rejection in peer relationships. In addition, ADHD subtype has been shown to influence children's social impairments; specifically, children with ADHD-combined (ADHD-C) are more likely to be actively rejected, whereas children with ADHD-inattentive (ADHD-I) are more likely to be neglected and socially isolated (Hodgens, Cole, \& Boldizar, 2000). Results of the Multimodal Treatment of Children with ADHD (MTA) study demonstrated that $52 \%$ of children with ADHD fall into the rejected category and $60 \%$ of children with ADHD have peer rejection scores two or more standard deviations above the mean (see Hoza, 2007, and Hoza, Mrug, et al., 2005, for reviews). Similar findings have emerged in adolescent populations. For example, Bagwell and colleagues (2001) found that childhood ADHD is a predictor of impaired peer functioning and peer rejection in adolescence, and that adolescents with ADHD were more likely to experience peer rejection than were typically developing adolescents. Moreover, Mrug and colleagues (2012) found that peer rejection in adolescence may contribute to further negative outcomes, such as increased internalizing symptoms, which may impact future peer interactions.

Research also suggests that peer rejection of children with ADHD is likely to occur within several hours, or even minutes, of interacting with unfamiliar peers (Hodgens et al., 2000). For example, Hodgens and colleagues (2000) found that children with ADHD were more likely than typically developing controls to receive peer nominations on items describing being teased or excluded by peers following three 20-min play sessions. Sibley and colleagues (2010) observed a similar phenomenon in a sample of adolescents with ADHD. Due to the swiftness with which children and adolescents with ADHD develop enduring, negative social reputations, it may be difficult to change peer group perceptions and the negative outcomes associated with them.

According to previous research, rejected children tend to experience negative outcomes, such as school avoidance and dropout, and continued peer exclusion and maltreatment (Buhs, Ladd, \& Herald, 2006). These effects may persist into adulthood and may manifest as

Journal of Attention Disorders, Vol 19, No. 10 (October 2015): pg. 844-855. DOI. This article is (C) SAGE Publications and permission has been granted for this version to appear in e-Publications@Marquette. SAGE Publications does not grant permission for this article to be further copied/distributed or hosted elsewhere without the express permission from SAGE Publications. 
poor educational and occupational competence (Bagwell et al., 1998; Mikami \& Hinshaw, 2006). More specifically, Mikami and Hinshaw (2006) found that peer rejection and ADHD in childhood predicted decreases in adolescent academic achievement, even while controlling for childhood academic achievement. In addition, the study found that perceived academic competence in childhood appeared to function as a protective factor against externalizing behavior and internalizing symptoms in adolescence (Mikami \& Hinshaw, 2006). Moreover, Barkley (2006) stated that, following repeated social rejection in childhood, adolescents with ADHD are more likely to join deviant peer groups. Finally, Mayeux, Bellmore, and Cillessen (2007) found that rejected children also are at a greater risk of future adjustment difficulties (e.g. aggression and anxiety).

Peer victimization, or bullying, is defined as repeated physical, verbal, or psychological abuse of victims by perpetrators who intend to hurt them (Olweus, 1994). Bullying may take the form of overt aggression, such as physical fighting, or relational aggression, such as social exclusion and spreading rumors about the victim (Olweus, 1994). Children and adolescents with ADHD are frequently involved in school bullying as either bullies, victims, or bully/victims (Bacchini, Affuso, \& Trotta, 2008). Each of these roles in bullying incidents increases the likelihood of peer rejection and may develop when children react to peer victimization passively (victims) or aggressively (bullies; Bacchini et al., 2008). Previous research has demonstrated that children with ADHD are significantly more likely to be victims of bullying than their typically developing peers (Holmberg \& Hjern, 2008; Taylor, Saylor, Twyman, \& Macias, 2010). In addition, Holmberg and Hjern (2008) found that $24 \%$ of 10 -year-old boys with ADHD reported bullying peers, while $35 \%$ reported being victimized by peers. This is compared with $17 \%$ of typically developing peers who reported being victimized (Holmberg \& Hjern, 2008). However, Taylor and colleagues (2010) found that children with ADHD were no more likely to report bullying behavior toward peers than were typical children. Moreover, children labeled as victims were significantly more likely to endorse emotional problems, such as depressive symptoms, than those who were not victims of bullying (Taylor et al., 2010). Furthermore, Bacchini and colleagues (2008) found that children with ADHD who were bullies or victims shared similar characteristics, such as poor emotion regulation and problem-solving skills. More permission has been granted for this version to appear in e-Publications@Marquette. SAGE Publications does not grant permission for this article to be further copied/distributed or hosted elsewhere without the express permission from SAGE Publications. 
specifically, the poor emotion regulation skills exhibited by bullies and victims may lead them to express more negative affect, such as anger, sadness, and anxiety in peer interactions (Bacchini et al., 2008).

Peer relationship difficulties, such as an absence of mutual friendships, peer rejection, and bullying, represent a significant domain of impairment in youth with ADHD. Chronic peer relationship difficulties may contribute to future negative outcomes, including school dropout, substance abuse, and psychopathology. According to the literature, youth with ADHD are likely to exhibit specific social skills deficits that contribute to peer relationship difficulties.

\section{Primary Social Skills Deficits in Children and Adolescents With ADHD}

The primary social skills deficits experienced by youth with ADHD can be categorized into three broad domains: disruptive/inappropriate social behaviors, sociocognitive and social problem-solving deficits, and emotion regulation difficulties. Each of these domains will be reviewed in detail in the following sections.

\section{Disruptive/Inappropriate Social Behaviors}

Children and adolescents with ADHD tend to demonstrate inappropriate social behaviors with peers, such as impulsivity, intrusiveness, and hostility, and tend to lack appropriate social skills, such as sharing, cooperation, and turn taking (see Wehmeier, Schacht, \& Barkley, 2010, for reviews). Social functioning difficulties may also be evident in children's play behavior (Cordier et al., 2010). For example, Cordier and colleagues (2010) examined the play behavior of children with ADHD during a 20-min free play session. During a cooperative play task, children with ADHD-hyperactive-impulsive (ADHD-HI) and ADHD-C demonstrated significantly less sharing and support of others than did children with ADHD-I. More specifically, the researchers found that children with ADHD-HI and ADHD-C demonstrated low scores in several categories, including "sharing," "supporting the play of others," and "social play" (Cordier et al., 2010). In addition, children with ADHD-HI and ADHD-C demonstrated high scores in the "mischief" and "clowning" categories (Cordier et al.,

Journal of Attention Disorders, Vol 19, No. 10 (October 2015): pg. 844-855. DOI. This article is (C SAGE Publications and permission has been granted for this version to appear in e-Publications@Marquette. SAGE Publications does not grant permission for this article to be further copied/distributed or hosted elsewhere without the express permission from SAGE Publications. 
2010). These findings suggest that play behavior in children with ADHD may vary based on subtype diagnosis.

An additional area of impairment for youth with ADHD is peer group entry (Ronk, Hund, \& Landau, 2011). According to a seminal theory developed by Dodge, Schlundt, Schocken, and Delugach (1983), socially competent children attempt to gain peer group entry by using a sequence of behaviors that evolve from "low risk" to "high risk." For example, a child may begin the peer group entry process by standing near a new peer group to gain a better understanding of the group's norms (Dodge et al., 1983). The child may then attempt to match the group members' behavior prior to joining the group by mirroring the group's activity alongside the group (Dodge et al., 1983). Children who are not classified as socially competent are more likely to begin by using intrusive, high-risk behaviors, such as engaging in off-topic conversation and will likely be perceived by peers as socially inappropriate (Dodge et al., 1983).

In a recent study, Ronk and colleagues (2011) examined peer group entry behaviors in boys with ADHD during a 1-hr simulated play date with two typically developing peers ("hosts"). Results of the study indicated that boys with and without ADHD used the same number of competent peer entry strategies (e.g., synchronous behavior), but that boys with ADHD used twice as many attention-getting strategies (e.g., disruption) and talked significantly more about themselves than boys without ADHD (Ronk et al., 2011). Overall, boys with ADHD were rated as using an "excessive" number of high-risk entry strategies and received significantly fewer host invitations to enter play than their typically developing peers (Ronk et al, 2011). The absence of appropriate peer entry strategies utilized by boys with ADHD indicates a lack of appropriate social knowledge and sociocognitive skills.

\section{Sociocognitive and Social Problem-Solving Deficits}

Children acquire appropriate social knowledge and skills through observational learning and attention to social feedback, a skill that is commonly impaired in children with ADHD (see Bacchini et al., 2008, and Hoza, 2007, for reviews). Poor attention in social interactions may lead to misattributions about the behavior and intentions of peers (Sibley et al., 2010). Moreover, poor attention to social feedback may permission has been granted for this version to appear in e-Publications@Marquette. SAGE Publications does not grant permission for this article to be further copied/distributed or hosted elsewhere without the express permission from SAGE Publications. 
lead to inaccurate interpretations of social success and failure in children and adolescents with ADHD.

For example, Hoza, Waschbusch, Pelham, Molina, and Milich (2000) examined responses to social success and failure in boys with and without ADHD. In the study, boys with ADHD participated in two experimental interactions with a typically developing confederate. Researchers explained to the participants that they were needed to help recruit new children (confederates) to participate in a summer program and the confederates were instructed to respond either positively (success condition) or negatively (failure condition). Confederates were instructed to use predefined responses and behaviors to ensure clear communication of either success or failure. Interactions were coded by trained raters for 20 behaviors, including participant responsiveness, frustration, effectiveness, and selfdisclosure. Results of the study indicated that boys with ADHD were rated as less socially effective than typically developing controls (Hoza et al., 2000). In addition, boys with ADHD were more likely than controls to rate themselves favorably on measures of social competence following an unsuccessful interaction (Hoza et al., 2000). Finally, boys with ADHD were more likely than controls to attribute successful interactions to external, uncontrollable factors rather than their own behavior (Hoza et al., 2000).

An additional area of social impairment in youth with ADHD is inadequate social problem-solving and perspective-taking skills. For example, Sibley and colleagues (2010) found that adolescents had difficulty generating appropriate and effective responses to hypothetical peer interaction situations and performed poorly on tasks that assessed understanding of cause and effect in social situations. Moreover, King and colleagues (2009) found that children with ADHD generated more hostile and aggressive responses to hypothetical peer provocation scenarios than did typically developing children. These findings support previous research results indicating that children with ADHD are particularly reactive to provocation from peers (King et al., 2009). Furthermore, children with ADHD tend to have poor social perspective taking skills and demonstrate less empathy toward peers (Barkley, 2006). Barkley (2006) hypothesized that poor inhibitory control, related to frontal lobe impairment, may be related to difficulty in inhibiting one's own responses long enough to consider and permission has been granted for this version to appear in e-Publications@Marquette. SAGE Publications does not grant permission for this article to be further copied/distributed or hosted elsewhere without the express permission from SAGE Publications. 
understand another child's perspective. Marton, Wiener, Rogers, Moore, and Tannock (2009) also examined empathy and social perspective taking in children with and without ADHD. Results of the study indicated that children with ADHD were rated as less empathic and having poorer social perspective taking skills than children without ADHD (Marton et al., 2009). Furthermore, children with ADHD were able to generate fewer strategies to solve interpersonal dilemmas than typically developing controls (Marton et al., 2009).

Finally, children with ADHD tend to have poor self-monitoring skills and have difficulty evaluating their own social behavior (Hoza et al., 2000). In fact, many children with ADHD tend to overestimate their social competence, which has been demonstrated when comparing self-reports with parent and teacher reports (Heiman, 2005; Hoza et al., 2004, Hoza, Pelham, Dobbs, Owens, \& Pillow, 2002; Ohan \& Johnston, 2011). This phenomenon is known as positive illusory bias, which has been defined as a child's overestimation of his or her social competence in relation to his or her actual social competence (Ohan \& Johnston, 2011). Hoza and colleagues (2002) examined positive illusory bias in boys with and without ADHD. Results of the study indicated that boys with ADHD tended to overestimate their academic, social, and behavioral competence significantly more than typically developing controls (Hoza et al., 2002). In addition, while the presence of depressive symptoms was related to reduced discrepancies between self-perceptions and other perceptions of competence for boys with ADHD, ratings of self-competence in the depressed subgroup remained significantly more inflated relative to controls (Hoza et al., 2002).

In an extension of the existing literature, Ohan and Johnston (2011) examined positive illusory bias and social competence in girls with and without ADHD. Results of the study indicated that girls with ADHD overestimated their social competence relative to parent and teacher reports and a coded laboratory observation task (Ohan \& Johnston, 2011). Moreover, girls with ADHD were significantly more likely to overestimate their social competence than typically developing controls (Ohan \& Johnston, 2011). Furthermore, for girls with ADHD, overestimates of social competence were associated with externalizing symptoms and poor psychosocial adjustment; this relationship was not observed for girls without ADHD (Ohan \& permission has been granted for this version to appear in e-Publications@Marquette. SAGE Publications does not grant permission for this article to be further copied/distributed or hosted elsewhere without the express permission from SAGE Publications. 
Johnston, 2011). Relatedly, Hoza and colleagues (2002) postulate that the overestimation of social competence may be the result of inadequate knowledge of appropriate social behaviors, which may lead to inaccurate monitoring of successful and unsuccessful social interactions. Thus, interventions aimed at increasing appropriate social knowledge and self-monitoring skills may help to address these deficits.

\section{Emotion Regulation Difficulties}

Impulsivity and emotion regulation difficulties also contribute to problematic peer relationships in youth with ADHD (Bacchini et al., 2008). Specific examples of emotional impairment include excessive expression of negative emotions, decreased tolerance for frustration, and reduced empathy (Barkley 2006). Melnick and Hinshaw (2000) observed that boys with ADHD exhibited greater difficulty with emotion regulation (as evidenced by "strong venting" and aggression) during a model-building task than boys without ADHD. In addition, Normand and colleagues (2011) found that children with ADHD displayed more intense emotions than their typically developing friends during an interaction task. Specifically, children with ADHD tended to be more dominant and display more negative affect during a game task (Normand et al., 2011).

Researchers have hypothesized that the emotion regulation difficulties observed in children and adolescents with ADHD may be related to impairment in the executive functioning system of the brain (Barkley, 2006). The executive functioning system is involved in several cognitive processes, including inhibition and emotion regulation (Barkley, 2006). Thus, dysfunction in this specific area of the brain may be related to disinhibition of extreme and inappropriate emotional reactions (Barkley, 2006). Previous research has demonstrated that children with ADHD also tend to have more difficulty accurately recognizing and identifying the emotions of others than typically developing peers (Da Fonseca, Seguier, Santos, Poinso, \& Derulle, 2009).

Da Fonseca and colleagues (2009) further examined emotion recognition in children and adolescents with ADHD. For the study, participants examined photographs depicting contextual scenes in

Journal of Attention Disorders, Vol 19, No. 10 (October 2015): pg. 844-855. DOI. This article is @ SAGE Publications and permission has been granted for this version to appear in e-Publications@Marquette. SAGE Publications does not grant permission for this article to be further copied/distributed or hosted elsewhere without the express permission from SAGE Publications. 
which one of the faces was "masked" and were required to choose the appropriate face from three emoticon response choices (Da Fonseca et al., 2009). Results of the study indicated that children and adolescents with ADHD were less accurate at using contextual evidence to understand emotions than typically developing controls (Da Fonseca et al., 2009). These findings suggest that children and adolescents with ADHD exhibit deficits in emotional recognition and processing that may influence social relationships (Da Fonseca et al., 2009). In a related study, Kats-Gold, Besser, and Priel (2007) examined emotion recognition skills in children at risk of ADHD through a computerized task that assessed speed and accuracy of emotion recognition. Results of the study indicated that boys at risk of ADHD demonstrated impairment in emotion recognition skills compared with typically developing controls (Kats-Gold et al, 2007). More specifically, at-risk boys needed more time to identify emotional expressions and demonstrated less accuracy even while accounting for the additional time. The researchers postulated that children with ADHD may have less developed problem-solving skills when failing to recognize others' emotions, and thus may utilize poor social skills during those interactions (Kats-Gold et al., 2007).

Furthermore, ADHD subtype also may influence children's emotion regulation skills; specifically, children with ADHD-C tend to be more aggressive and have greater difficulty regulating emotions, whereas ADHD-I children tend to be more passive and shy (Hodgens et al., 2000). Similarly, Maedgen and Carlson (2000) found that children with ADHD-C are more likely to exhibit more intense emotional reactions, both positive and negative, than children with ADHD-I, suggesting that children with ADHD-C have more difficulty with emotion regulation than children with ADHD-I.

In summary, children and adolescents with ADHD experience significant peer relationship difficulties and social skills impairment that lead to both short- and long-term consequences, such as peer rejection, internalizing problems, school dropout, and substance abuse. Furthermore, many of the negative outcomes of impaired social functioning persist into adulthood. Previous research suggests that intrusive social behaviors, sociocognitive deficits, and emotion regulation difficulties contribute to negative peer outcomes for children and adolescents with ADHD. However, previous research also suggests

Journal of Attention Disorders, Vol 19, No. 10 (October 2015): pg. 844-855. DOI. This article is (C) SAGE Publications and permission has been granted for this version to appear in e-Publications@Marquette. SAGE Publications does not grant permission for this article to be further copied/distributed or hosted elsewhere without the express permission from SAGE Publications. 
that the presence of at least one mutual friendship may serve as a protective factor against negative peer outcomes, such as peer victimization.

\section{Peer Functioning Interventions for ADHD}

\section{Social Skills Training and Friendship-Building Programs}

While there are a limited number of studies examining peer functioning interventions for youth with ADHD, social skills training programs have been widely utilized in the ADHD treatment literature. The primary goal of social skills training programs is to teach appropriate social skills and behaviors to children with peer functioning difficulties (Mrug et al., 2001). Many social skills interventions involve didactic group instruction, as well as opportunities for behavioral rehearsal of new skills with other group members (Mrug et al., 2001). Previous research on the effectiveness of social skills interventions has demonstrated mixed effectiveness, with little to no long-term improvement in peer relationship functioning (Hoza, Gerdes, et al., 2005). As a result of unsatisfactory outcomes, researchers in the MTA Cooperative Group examined the effectiveness of modified social skills programs in the context of the Summer Treatment Program (STP) for children and adolescents with ADHD (Antshel \& Remer, 2003; Hoza et al., 2003; Mrug et al., 2001; Pfiffner \& McBurnett, 1997). The following section will provide a description of the social skills training component of the STP and will describe the outcomes of both traditional and modified social skills interventions utilized in the program.

\section{Summer Treatment Program}

The STP is an intensive 8-week treatment program for children and adolescents (aged 5-15) with ADHD. Participants in the STP receive behavior modification training, provided by trained counselors, in classroom, recreational, and peer contexts with the goal of improving group functioning, peer functioning, and compliance with adult instructions (Pelham \& Hoza, 1996). The STP is primarily child focused, but does include weekly group parent training sessions, which serve to assist with the generalization of behavior modification

Journal of Attention Disorders, Vol 19, No. 10 (October 2015): pg. 844-855. DOI. This article is (C SAGE Publications and permission has been granted for this version to appear in e-Publications@Marquette. SAGE Publications does not grant permission for this article to be further copied/distributed or hosted elsewhere without the express permission from SAGE Publications. 
techniques to the home environment. Furthermore, children and adolescents enrolled in the STP may choose to participate in a medication management program (Pelham \& Hoza, 1996). Brief groupbased social skills training sessions also are provided daily. During social skills training, children learn new skills, such as validation, cooperation, and communication, and engage in behavioral rehearsal with other group members. Children receive positive reinforcement of appropriate social skills from counselors and other group members throughout the program day (Pelham \& Hoza, 1996).

Previous studies examining the overall effectiveness of the STP on behavior modification and symptom reduction have demonstrated that the program provides comparable effects with a medication regimen and is more effective than a no-treatment condition (see Chronis, Chacko, Fabiano, Wymbs, \& Pelham, 2004, and Fabiano et al., 2007, for reviews). However, despite improvements in behavioral functioning (e.g., increased compliance) in both recreational and classroom contexts, participants did not demonstrate long-term improvements in peer functioning, as measured by peer nominations (Hoza, Gerdes, et al., 2005).

Researchers have examined the effectiveness of modified versions of traditional social skills training programs. For example, Pfiffner and McBurnett (1997) modified the social skills program to include a parent generalization component, which was implemented through an 8-week group program. The study compared the treatment effects of a traditional social skills group with a social skills group with a parent generalization component. Children in both conditions attended eight 90-min group sessions, which included a didactic component, role-playing, and behavioral rehearsal. Moreover, children were assigned weekly homework relevant to each skill lesson (Pfiffner \& McBurnett, 1997). For example, children were asked to practice one social skill in a peer context throughout the week. Parent sessions included review of the skill lesson that the children learned and observation of the child group through a one-way observation window. In addition, parents were instructed to prompt their child to use his or her social skills throughout the week. Results of the study indicated that children in the social skills only group and the social skills plus parent generalization group demonstrated improved social interaction skills as rated by parent report (Pfiffner \& McBurnett, 1997). However, permission has been granted for this version to appear in e-Publications@Marquette. SAGE Publications does not grant permission for this article to be further copied/distributed or hosted elsewhere without the express permission from SAGE Publications. 
children in the social skills only group demonstrated less generalization to other settings than children in the parent generalization group (Pfiffner \& McBurnett, 1997). Furthermore, parents in both groups expressed interest in adding the parent generalization component to future social skills groups (Pfiffner \& McBurnett, 1997).

Through another modification of traditional social skills training, the STP also has targeted dyadic peer relationships through a "buddy system" intervention (Hoza et al, 2003; see Mrug et al., 2001, for reviews). For the study, each participating child was paired with another child from the program based on the children's friendship preferences. Children participated in a variety of shared activities with their buddies, including being partners during recreational activities and classroom projects, sitting together during lunchtime and field trips, and sharing points earned through the behavior modification system (Hoza et al., 2003). In addition, parents were asked to arrange get-togethers with the two children outside of the program environment. Results of the study indicated that children paired with a less disruptive buddy demonstrated more positive outcomes (as evidenced by quality of friendships) than children paired with a more disruptive buddy (Mrug et al., 2001). Furthermore, parents were less likely to arrange weekly play dates when their child was paired with a more disruptive buddy (Hoza et al., 2003; Mrug et al., 2001). Hoza and colleagues (2003) hypothesized that parents of children paired with a disruptive buddy may have been concerned about the effect of the buddy's negative behavior on their own child's behavior.

Furthermore, the authors highlight the importance of teaching parents how to supervise get-togethers to minimize conflict and promote positive interactions (Hoza et al., 2003). Overall, children whose parents consistently followed through with the "buddy system" intervention demonstrated more positive outcomes (as evidenced by improved social skills, problem-solving, self-esteem, and happiness) at the end of the program (Hoza et al., 2003; Mrug et al., 2001). This provides support for the importance of get-togethers and parental involvement in psychosocial interventions. The authors highlight the importance of developing "buddy system" interventions that can be implemented outside of the STP setting (e.g., community or school settings), due to the limited accessibility of the STP (Mrug et al., 2001). Furthermore, social skills training is typically just one permission has been granted for this version to appear in e-Publications@Marquette. SAGE Publications does not grant permission for this article to be further copied/distributed or hosted elsewhere without the express permission from SAGE Publications. 
component of a larger behavioral intervention program, which focuses on compliance, academic achievement, and athletic skills. Thus, the authors highlight the importance of implementing "buddy system" interventions independent of larger behavioral intervention programs (Hoza et al., 2003).

\section{Clinical Implications}

Several types of peer functioning interventions have been utilized for youth with ADHD, including traditional social skills training, social skills training with parent generalization, and social skills training with a dyadic friendship component. Interventions involving parent generalization or dyadic friendship components have resulted in greater overall improvement in participating children than programs without these components (Hoza et al., 2003; Mrug et al., 2001; Pfiffner \& McBurnett, 1997). To establish effective peer functioning interventions for children and adolescents with ADHD, critical review and evaluation of the advantages and limitations of current interventions is essential.

Currently, two main limitations of peer functioning interventions have been identified in the literature, including (a) lack of long-term, intensive focus on peer functioning and (b) lack of parental involvement in peer functioning interventions. To address these limitations, modifications to current clinical practice should be considered.

\section{Lack of Long-Term Focus on Peer Functioning Interventions}

Researchers have identified a need for long-term intervention programs that focus solely on peer difficulties in children and adolescents with ADHD (Frankel \& Whitham, 2011; Hoza, 2007). The effectiveness of peer functioning interventions can be enhanced by addressing two components: (a) implementation of peer functioning interventions independent of larger behavior modification programs, and (b) implementation of long-term, comprehensive interventions that include structured homework assignments and generalization components. Despite the significance of peer relationship difficulties 
for youth with ADHD, peer functioning interventions are often secondary to behavior modifications programs designed to reduce ADHD symptoms in home and classroom contexts. More specifically, peer functioning interventions are typically part of behaviorally focused programs, such as the MTA study, that also include parent training and classroom management components (Hoza, 2007). Furthermore, participation in multicomponent treatment programs may make it difficult to sufficiently focus on all treatment components. Thus, children enrolled in multicomponent treatment programs may demonstrate improvements in ADHD symptom reduction (e.g., decreased noncompliance) but fail to demonstrate gains in peer functioning (Hoza, Gerdes, et al., 2005). Therefore, it can be argued that parents and children may be better able to focus on improving peer relationships following successful completion of parent training and school interventions. Furthermore, since previous research has demonstrated that greater gains are observed when participants demonstrate greater treatment compliance, parents and children who have demonstrated a commitment to behavior modification programs may be better able to benefit from intensive peer functioning programs.

Moreover, peer functioning interventions should be long-term, comprehensive, and structured. For example, traditional social skills training programs are typically short term (e.g. 6-8 weekly sessions), primarily child focused, and require minimal out-of-group homework. Thus, it is not surprising that traditional social skills training programs have not demonstrated significant, long-lasting improvements in social skills and peer relationships for children with ADHD (Hoza, 2007; Hoza, Gerdes, et al., 2005; Mrug et al., 2001). However, long-term programs (e.g., 12-14 weekly sessions) that include structured, multifaceted homework assignments, such as in-group phone calls and out-of-group get-togethers, have demonstrated favorable results, such as significant improvement over the waitlist control group, generalization to out-of-group contexts, and maintenance of treatment gains several months posttreatment for some adolescent populations (Laugeson et al., 2009). Therefore, peer functioning interventions should be implemented independent of larger behavior modification programs, and should include comprehensive, structured sessions with weekly homework assignments. permission has been granted for this version to appear in e-Publications@Marquette. SAGE Publications does not grant permission for this article to be further copied/distributed or hosted elsewhere without the express permission from SAGE Publications. 


\section{Lack of Parent Involvement in Social Skills and Friendship-Building Interventions}

In addition to long-term, comprehensive interventions, researchers have identified a need for intensive parental involvement in peer functioning interventions (Frankel \& Mintz, 2011; Frankel et al., 1997; Mikami, 2010). Specifically, Frankel and colleagues (1997) noted that few social skills programs require parent involvement, despite the fact that parents are generally responsible for scheduling children's play dates. Previous research has provided evidence to suggest that parent involvement may be related to greater effectiveness in peer functioning over primarily child-focused interventions. Specifically, there is evidence to suggest that parent involvement may assist with generalization of social interaction skills outside of the treatment setting, as parents are able to provide direction and feedback in out-of-session contexts (Frankel et al., 1997; Mikami, 2010; Pfiffner \& McBurnett, 1997). For example, previous research has demonstrated that interventions involving a concurrent parent group resulted in improved social interaction skills, friendship quality, and increased frequency of out-of group get-togethers (Laugeson et al. 2009; Pfiffner \& McBurnett, 1997). Furthermore, since parents are typically responsible for scheduling and supervising children's play dates and adolescents' get-togethers, they may be able to assist with the establishment of a lasting friendship (Frankel \& Mintz, 2011). Parent components of friendship-building programs allow clinicians to train parents to identify potential friends for their children and foster friendships through enrollment in appropriate extracurricular activities and supervision of out-of-group get-togethers (Frankel et al., 1997; Mikami, 2010). Therefore, peer functioning interventions should include a concurrent parent group focused on training parents to identify and reinforce appropriate social interaction skills and supervise dyadic peer interactions.

\section{Children's Friendship Training Program}

One such program is the Children's Friendship Training (CFT) program that was developed by Frankel and Myatt (2003). The CFT is a 12-week group-based intervention designed for school-aged children with peer functioning difficulties. The CFT program consists of weekly permission has been granted for this version to appear in e-Publications@Marquette. SAGE Publications does not grant permission for this article to be further copied/distributed or hosted elsewhere without the express permission from SAGE Publications. 
90-min structured sessions for both children and their parents (Frankel \& Myatt, 2003). Group sessions are held in a community outpatient setting and include approximately 6 to 10 children and their parent(s). Parent and child groups are held concurrently and include both didactic and behavioral rehearsal components (Frankel \& Myatt, 2003). Each child session consists of homework review, a didactic lesson, behavioral rehearsal, and a coached play interaction, during which children receive feedback on socialization skills. Throughout the program, children are taught a variety of socialization skills, including conversational skills, peer group entry, good sportsmanship, appropriate responses to teasing, and conflict resolution (Frankel \& Myatt, 2003). Group sessions address both behavioral and affective responses in peer situations. Parent sessions consist of homework review, discussion of the child's didactic lesson, and discussion of anticipated problems with out-of-group tasks. Homework completion is an essential component of the CFT program. Parents and children are given weekly homework assignments to assist with the acquisition of new skills learned during CFT sessions. Homework assignments typically involve making phone calls to other group members and hosting get-togethers with peers outside of the group.

Frankel and colleagues (1997) conducted a treatment study to examine the effectiveness of the CFT program for children, aged 6 to 12 years, with ADHD. Thirty-five children with ADHD participated in the treatment group and 12 children with ADHD participated in the waitlist control group. The results of the study indicated that, following the intervention, children in the treatment group demonstrated lower aggression scores and higher assertion and self-control scores (as rated by teachers) than children in the waitlist control group (Frankel et al., 1997). In addition, $83.4 \%$ of children in the treatment group demonstrated significantly better outcomes on all treatment variables compared with the average waitlist control child (Frankel et al., 1997). Furthermore, results of more recent studies have demonstrated that treatment gains generalized outside of the treatment setting, and that treatment gains were maintained at a 3-month follow-up (Frankel \& Myatt, 2007). An additional study conducted by Frankel and Mintz (2011) found that children referred to the CFT program demonstrated significantly fewer parent-reported get-togethers and significantly greater conflict during get-togethers than children in a communitypermission has been granted for this version to appear in e-Publications@ Marquette. SAGE Publications does not grant permission for this article to be further copied/distributed or hosted elsewhere without the express permission from SAGE Publications. 
based control group, further emphasizing the importance of a program focused on arranging out-of-group get-togethers.

\section{Program for the Evaluation and Enrichment of Relational Skills}

The Program for Evaluation and Enrichment of Relational Skills (PEERS), adapted from CFT, is an intensive 14-week friendshipbuilding intervention designed to assist adolescents in learning appropriate social skills, expanding their peer network, and managing peer victimization (Laugeson \& Frankel, 2010). The PEERS program is structured similarly to the CFT program with didactic and behavioral rehearsal components, as well as structured out-of-group homework assignments. A primary outcome of the PEERS program is for adolescents to develop at least one close, dyadic friendship (Laugeson et al., 2009). Furthermore, PEERS places a particular emphasis on the generalization of social skills outside of the treatment setting (Laugeson et al., 2009). The PEERS program has been implemented with several clinical populations, including adolescents with autism spectrum disorders (Laugeson et al., 2009). However, there are no published studies on the effectiveness of PEERS for teens with ADHD. Results of a study conducted by Laugeson and colleagues (2009) demonstrated that adolescents with ASDs exhibited improvement in social knowledge, frequency of hosted get-togethers, friendship quality, and overall social skills compared with adolescents in the waitlist control group. Favorable outcomes of PEERS for teens with ASDs provide promising evidence for its potential effectiveness with other teen populations, such as teens with ADHD.

\section{Future Directions}

\section{PEERS for Adolescents With ADHD}

To investigate the effectiveness of PEERS in adolescents with ADHD, treatment studies implementing a treatment-waitlist control design should be conducted to examine clinical outcomes. In addition, it is important to carefully select outcome measures to accurately assess treatment effectiveness. 
To date, many treatment studies have utilized primarily peer nomination, or peer group acceptance, as the primary treatment outcome measure (Hoza, Mrug, et al., 2005; MTA Cooperative Group, 1999). However, recently researchers have highlighted the importance of targeting dyadic friendship formation rather than peer group acceptance as the primary outcome of peer functioning interventions (Hoza, 2007; Mikami, 2010; Normand et al., 2011). Peer group status is difficult to change because negative social reputations develop early for children with ADHD and tend to remain stable over time (Mikami, 2010). Therefore, it may be more beneficial to use dyadic friendship formation as the primary outcome measure for peer intervention studies. Fostering the development of one mutual friendship may be a more realistic goal and may lead to generalization of newly acquired skills outside of the treatment setting, such as during get-togethers (Mikami, 2010). In addition, previous research has illustrated that the presence of at least one mutual friendship may function as a protective factor against peer rejection and victimization, and may lead to greater gains in peer acceptance in the long term (Bollmer, Millich, Harris, \& Maras, 2005). Furthermore, social competence and skills appropriate for dyadic interactions may be more beneficial than acceptance by the entire peer group, as this approach requires changing the perception of only one peer (Mikami, 2010).

\section{Conclusion}

Peer relationship difficulties are a significant area of impairment for $50 \%$ to $70 \%$ of youth with ADHD (Hoza, 2007). Specifically, youth with ADHD frequently experience peer stigmatization, rejection, and victimization, which are associated with negative long-term outcomes, such as academic difficulties, psychopathology, and continued social difficulties (Bagwell et al., 1998). While effective treatment protocols for behavior management in home and classroom contexts are well established, effective peer functioning interventions require additional investigation. Pharmacological treatments may be effective in reducing negative social behaviors, but they do not contribute to an increase in positive social behaviors and do not change peer status in youth with ADHD (MTA Cooperative Group, 1999). This review examines current peer functioning interventions and summarizes current

Journal of Attention Disorders, Vol 19, No. 10 (October 2015): pg. 844-855. DOI. This article is (C SAGE Publications and permission has been granted for this version to appear in e-Publications@Marquette. SAGE Publications does not grant permission for this article to be further copied/distributed or hosted elsewhere without the express permission from SAGE Publications. 
recommendations for clinical modifications and future research endeavors with this population.

Traditional social skills training programs are typically underutilized and have not demonstrated significant long-term improvement in peer functioning (Hoza, Gerdes, et al., 2005). Furthermore, researchers have highlighted the importance of longterm programs (e.g., 12-14 weekly sessions) that include structured homework assignments and intensive parental involvement in treatment (Frankel \& Whitham, 2011; Hoza, 2007). Friendshipbuilding interventions, such as PEERS, that include the recommended components have demonstrated positive outcomes (e.g., development of a close friendship) for several adolescent populations, including teens with ASD (Laugeson et al., 2009). However, the effectiveness of friendship-building programs for teens with ADHD requires further investigation. To assess treatment effectiveness, outcome measures should be carefully selected to provide a multimethod, multi-informant assessment of peer-related difficulties. Furthermore, focusing on the development of one close mutual friendship may lead to greater treatment gains than targeting the perceptions of the entire peer group (Frankel \& Myatt, 2007; Frankel et al., 1997; Laugeson et al, 2009). To sufficiently address peer relationship difficulties in children and adolescents with ADHD, peer functioning interventions should be made a part of the standard treatment recommendations in community clinic settings.

Declaration of Conflicting Interests The author(s) declared no potential conflicts of interest with respect to the research, authorship, and/or publication of this article.

Funding The author(s) received no financial support for the research, authorship, and/or publication of this article.

\section{References}

American Psychiatric Association. (2000). Diagnostic and statistical manual of mental disorders (4th ed., text rev.). Washington, DC: Author. Antshel K. M., Macias M., Barkley R. A. (2009). The child with attention deficit hyperactivity disorder. In David R. B., Bodensteiner J. B., 
NOT THE PUBLISHED VERSION; this is the author's final, peer-reviewed manuscript. The published version may be

accessed by following the link in the citation at the bottom of the page.

Mandelbaum D. E., Olson B. J. (Eds.), Child pediatric neurology (pp. 525-540). New York, NY: Demos Medical.

Antshel K. M., Remer R. (2003). Social skills training in children with attention deficit hyperactivity disorder: A randomized-controlled clinical trial. Journal of Clinical Child \& Adolescent Psychology, 32, 153-165.

Bacchini D., Affuso G., Trotta T. (2008). Temperament, ADHD, and peer relations among schoolchildren: The mediating role of school bullying. Aggressive Behavior, 34, 447-459. doi:10.1002/ab.20271

Bagwell C. L., Molina B. S., Pelham W. E., Hoza B. (2001). Attentiondeficit/hyperactivity disorder and problems in peer relations: Predictions from childhood to adolescence. Journal of the American Academy of Child \& Adolescent Psychiatry, 40, 1285-1292.

Bagwell C. L., Newcomb A. F., Bukowski W. M. (1998). Preadolescent friendships and peer rejection as predictors of adult. Child Development, 69, 140-153. doi:10.1111/j.1467-8624.1998.tb06139.x

Barkley R. A. (2006). Attention-deficit/hyperactivity disorder: A handbook for diagnosis and treatment. New York, NY: Guilford Press.

Barkley R. A., Fischer M., Edelbrock C. S., Smallish L. (1990). The adolescent outcome of hyperactive children diagnosed by research criteria: 1. An 8-year follow-up study. Journal of the American Academy of Child \& Adolescent Psychiatry, 29, 546-557.

Blachman D. R., Hinshaw S. P. (2002). Patterns of friendship among girls with and without attention-deficit/hyperactivity disorder. Journal of Abnormal Child Psychology, 30, 625-640.

Bollmer J. M., Millich R., Harris M. J., Maras M. A. (2005). A friend in need: The role of friendship quality as a protective factor in peer victimization and bullying. Journal of Interpersonal Violence, 20,701712. doi: $10.1177 / 0886260504272897$

Buhs E. S., Ladd G. W., Herald S. L. (2006). Peer exclusion and victimization: Processes that mediate the relation between peer group rejection and children's classroom engagement and achievement. Journal of Educational Psychology, 98, 1-13.

Chronis A. M., Chacko A., Fabiano G. A., Wymbs B. T., Pelham W. E. (2004). Enhancements to the behavioral parent training paradigm for families of children with ADHD: Review and future directions. Clinical Child and Family Psychology Review, 7, 1-27. doi:10.1023/B:CCFP.0000020190.60808.a4

Cordier R., Bundy A., Hocking C., Einfeld S. (2010). Comparison of play with children with attention-deficit/hyperactivity disorder by subtypes.

Journal of Attention Disorders, Vol 19, No. 10 (October 2015): pg. 844-855. DOI. This article is (C SAGE Publications and permission has been granted for this version to appear in e-Publications@Marquette. SAGE Publications does not grant permission for this article to be further copied/distributed or hosted elsewhere without the express permission from SAGE Publications. 
NOT THE PUBLISHED VERSION; this is the author's final, peer-reviewed manuscript. The published version may be accessed by following the link in the citation at the bottom of the page.

Australian Occupational Therapy Journal, 57, 137-145. doi: $10.1111 / \mathrm{j} .1440-1630.2009 .00821 . x$

Da Fonseca D., Seguier V., Santos A., Poinso F., Derulle C. (2009). Emotion understanding in children with ADHD. Child Psychiatry \& Human Development, 40, 111-121. doi:10.1007/s10578-008-0114-9

Dodge K. A., Schlundt D. C., Schocken I., Delugach J. D. (1983). Social competence and children's sociometric status: The role of peer group entry strategies. Merrill-Palmer Quarterly, 29, 309-336.

Fabiano G. A., Pelham W. E.Jr., Gnagy E. M., Burrows-McClean L., Coles E. K., Chackoet A., Robb J. A. (2007). The single and combined effects of multiple intensities of behavior modification and methylphenidate for children with attention deficit hyperactivity disorder in a classroom setting. School Psychology Review, 36, 195-216.

Frankel F., Mintz J. (2011). Maternal reports of play dates of clinic referred and community children. Journal of Child and Family Studies, 20, 623630. doi:10.1007/s10826-010-9437-9

Frankel F., Myatt R. (2003). Children's friendship training. New York, NY: Brunner-Routledge.

Frankel F., Myatt R. (2007). Parent-assisted friendship training for children with autism spectrum disorders: Effects associated with psychotropic medication. Child Psychiatry \& Human Development, 37, 337-346.

Frankel F., Myatt R., Cantwell D. P., Feinberg D. T. (1997). Parent-assisted transfer of children's social skills training: Effects on children with and without attention-deficit/hyperactivity disorder. Journal of the American Academy of Child \& Adolescent Psychiatry, 36, 1056-1064.

Frankel F., Whitham C. (2011). Parent-assisted group treatment for friendship problems of children with autism spectrum disorders. Brain Research, 1380, 240-245. doi:10.1016/j.brainres.2010.09.047

Heiman T. (2005). An examination of peer relationships of children with and without attention deficit hyperactivity disorder. School Psychology International, 26, 330-339. doi:10.1177/0143034305055977

Hodgens J. B., Cole J., Boldizar J. (2000). Peer-based differences among boys with ADHD. Journal of Clinical Child Psychology, 29, 443-452. doi:10.1207/S15374424JCCP2903_15

Holmberg K., Hjern A. (2008). Bullying and attention-deficit-hyperactivity disorder in 10-year-olds in a Swedish community. Developmental Medicine \& Child Neurology, 50, 134-138. doi:10.1111/j.14698749.2007.02019.x

Hoza B. (2007). Peer functioning in children with ADHD. Ambulatory Pediatrics, 7, 101-106.

Journal of Attention Disorders, Vol 19, No. 10 (October 2015): pg. 844-855. DOI. This article is (C SAGE Publications and permission has been granted for this version to appear in e-Publications@Marquette. SAGE Publications does not grant permission for this article to be further copied/distributed or hosted elsewhere without the express permission from SAGE Publications. 
Hoza B., Gerdes A. C., Hinshaw S. P., Arnold L. E., Pelham W. E., Molina B. S., Wigal T. (2004). Self- perceptions of competence in children with ADHD and comparison children. Journal of Consulting and Clinical Psychology, 72, 382-391. doi:10.1037/0022-006X.72.3.382

Hoza B., Gerdes A. C., Mrug S., Hinshaw S. P., Bukowski W. M., Gold J. A., Wigal T. (2005). Peer-assessed outcomes in the multimodal treatment study of children with attention deficit hyperactivity disorder. Journal of Clinical Child \& Adolescent Psychology, 34, 74-86.

Hoza B., Mrug S., Gerdes A. C., Hinshaw S. P., Bukowski W. M., Gold J. A., Arnold L. E. (2005). What aspects of peer relationships are impaired in children with attention-deficit/hyperactivity disorder? Journal of Consulting and Clinical Psychology, 73, 411-423.

Hoza B., Mrug S., Pelham W. E., Greiner A. R., Gnagy E. M. (2003). A friendship intervention for children with attention-deficit/hyperactivity disorder: Preliminary findings. Journal of Attention Disorders, 6, 8798. doi:10.1177/108705470300600301

Hoza B., Pelham W. E., Dobbs J., Owens J. S., Pillow D. R. (2002). Do boys with attention- deficit/hyperactivity disorder have positive illusory self-concepts? Journal of Abnormal Psychology, 111, 268-278. doi: $10.1037 / 0021-843 X .111 .2 .268$

Hoza B., Waschbusch D. A., Pelham W. E., Molina B. S., Milich R. (2000). Attention-deficit/hyperactivity disordered and control boys' response to social success and failure. Child Development, 71, 432-446.

Hurtig T., Ebeling H., Taanila A., Miettunen J., Smalley S. L., Mc Gough J. J., Moilanen I. K. (2007). ADHD symptoms and subtypes: Relationship between childhood and adolescent symptoms. Journal of the American Academy of Child \& Adolescent Psychiatry, 46, 1605-1613.

Kats-Gold I., Besser A., Priel B. (2007). The role of simple emotion recognition skills among school aged boys at risk of ADHD. Journal of Abnormal Child Psychology, 35, 363-378. doi:10.1007/s10802-0069096-x

King S., Waschbusch D. A., Pelham W. E., Frankland B. W., Andrade B. F., Jacques S., Corkum P. V. (2009). Social information processing in elementary-school aged children with ADHD: Medication effects and comparisons with typical children. Journal of Abnormal Child Psychology, 37, 579-589. doi:10.1007/s10802-008-9294-9

Laugeson E. A., Frankel F. (2010). Social skills for teenagers with developmental and autism spectrum disorders: The PEERS manual. New York, NY: Routledge.

Laugeson E. A., Frankel F., Mogil C., Dillon A. R. (2009). Parent-assisted social skills training to improve friendships in teens with autism

Journal of Attention Disorders, Vol 19, No. 10 (October 2015): pg. 844-855. DOI. This article is (C SAGE Publications and permission has been granted for this version to appear in e-Publications@Marquette. SAGE Publications does not grant permission for this article to be further copied/distributed or hosted elsewhere without the express permission from SAGE Publications. 
NOT THE PUBLISHED VERSION; this is the author's final, peer-reviewed manuscript. The published version may be accessed by following the link in the citation at the bottom of the page.

spectrum disorders. Journal of Autism and Developmental Disorders, 39, 596-606. doi:10.1007/s10803-008-0664-5

Maedgen J. W., Carlson C. L. (2000). Social functioning and emotional regulation in the attention deficit hyperactivity disorder subtypes. Journal of Clinical Child Psychology, 29(1), 30-42. doi:10.1207/S15374424jccp2901_4

Marton I., Wiener J., Rogers M., Moore C., Tannock R. (2009). Empathy and social perspective taking in children with attentiondeficit/hyperactivity disorder. Journal of Abnormal Child Psychology, 37, 107-118. doi:10.1007/s10802-008-9262-4

Mayeux L., Bellmore A. D., Cillessen A. H. (2007). Predicting changes in adjustment using repeated measures of sociometric status. Journal of Genetic Psychology, 168, 401-424.

McQuade J. D., Hoza B. (2008). Peer problems in attention deficit hyperactivity disorder: Current status and future directions. Developmental Disabilities, 14, 320-324. doi:10.1002/ddrr.35

Melnick S. M., Hinshaw S. P. (2000). Emotion regulation and parenting in AD/HD and comparison boys: Linkages with social behaviors and peer preference. Journal of Abnormal Child Psychology, 28, 73-86. doi:10.1023/A: 1005174102794

Mikami A. Y. (2010). The importance of friendship for youth with attentiondeficit/hyperactivity disorder. Clinical Child and Family Psychology Review, 13, 181-198. doi:10.1007/s10-567-010-0067-y

Mikami A. Y., Hinshaw S. P. (2006). Resilient adolescent adjustment among girls: Buffers of childhood peer rejection and attentiondeficit/hyperactivity disorder. Journal of Abnormal Child Psychology, 34, 825-839.

Mrug S., Hoza B., Gerdes A. C. (2001). Children with attentiondeficit/hyperactivity disorder: Peer relationships and peer-oriented interventions. In Nangle D. W., Erdley C. A. (Eds.), The role of friendship in psychological adjustment (pp. 51-78). San Francisco, CA: Jossey-Bass.

Mrug S., Molina B. S., Hoza B., Gerdes A. C., Hinshaw S. P., Hectman L., Arnold L. E. (2012). Peer rejection and friendships in children with attention-deficit/hyperactivity disorder: Contributions to long-term outcomes. Journal of Abnormal Child Psychology, 40, 1013-1023. doi: $10.1007 / \mathrm{s} 10802-012-9610-2$

MTA Cooperative Group. (1999). A 14-month randomized clinical trial of treatment strategies for attention-deficit/hyperactivity disorder. Archives of General Psychiatry, 56, 1073-1086. doi:10.1001/archpsyc.56.12.1073

Journal of Attention Disorders, Vol 19, No. 10 (October 2015): pg. 844-855. DOI. This article is (C SAGE Publications and permission has been granted for this version to appear in e-Publications@Marquette. SAGE Publications does not grant permission for this article to be further copied/distributed or hosted elsewhere without the express permission from SAGE Publications. 
Normand S., Schneider B. H., Lee M. D., Masionneuve M. F., Keuhn S. M., Robaey P. (2011). How do children with ADHD (mis)manage their real-life dyadic friendships? A multi-method investigation. Journal of Abnormal Child Psychology, 39, 293-305. doi:10.1007/s10802-0109450-x

Ohan J. L., Johnston C. (2011). Positive illusions of social competence in girls with and without ADHD. Journal of Abnormal Child Psychology, 39, 527-539. doi:10.1007/s10802-010-9484-0

Olweus D. (1994). Bullying at school: Basic facts and effects of a school based intervention program. Journal of Child Psychology and Psychiatry, 35, 1171-1190. doi:10.1111/j.1469-7610.1994.tb01229.x

Pelham W. E.Jr., Hoza B. (1996). Intensive treatment: A summer treatment program for children with ADHD. In Hibbs E. D., Jensen P. S. (Eds.), Psychosocial treatments for child and adolescent disorders: Empirically-based strategies for clinical practice (pp. 311-340). Washington, DC: American Psychological Association.

Pfiffner L. J., McBurnett K. (1997). Social skills training with parent generalization: Treatment effects for children with attention deficit disorder. Journal of Consulting and Clinical Psychology, 65, 749-757.

Ronk M. J., Hund A. M., Landau S. (2011). Assessment of social competence of boys with attention-deficit/hyperactivity disorder: Problematic peer entry, host responses, and evaluations. Journal of Abnormal Child Psychology, 39, 829-840. doi:10.1007/s10802-011-9497-3

Sibley M. H., Evans S. W., Serpell Z. N. (2010). Social cognition and interpersonal impairment in young adolescents with ADHD. Journal of Psychopathology and Behavior Assessment, 32, 193-202. doi:10.1007/s10862-009-9152-2

Swords L., Heary C., Hennessy E. (2011). Factors associated with acceptance of peers with mental health problems in childhood and adolescence. Journal of Child Psychology and Psychiatry, 52, 933-941. doi: $10.1111 /$ j.1469-7610.2010.02351.x

Taylor L. A., Saylor C., Twyman K., Macias M. (2010). Adding insult to injury: Bullying experiences of youth with attention-deficit hyperactivity disorder. Children's Health Care, 39, 59-72. doi:10.1080/02739610903455152

Walker J. S., Coleman D., Lee J., Squire P. N., Friesen B. J. (2008). Children's stigmatization of childhood depression and ADHD: Magnitude and demographic variation in a national sample. Journal of the American Academy of Child \& Adolescent Psychiatry, 47, 912-920. doi: $10.1097 / \mathrm{CHI} .0 \mathrm{~b} 013 \mathrm{e} 318179961 \mathrm{a}$

Journal of Attention Disorders, Vol 19, No. 10 (October 2015): pg. 844-855. DOI. This article is (C SAGE Publications and permission has been granted for this version to appear in e-Publications@Marquette. SAGE Publications does not grant permission for this article to be further copied/distributed or hosted elsewhere without the express permission from SAGE Publications. 
NOT THE PUBLISHED VERSION; this is the author's final, peer-reviewed manuscript. The published version may be accessed by following the link in the citation at the bottom of the page.

Wehmeier P. M., Schacht A., Barkley R. A. (2010). Social and emotional impairment in children and adolescents with ADHD and the impact on quality of life. Journal of Adolescent Health, 46, 209-217. doi:10.1016.j.jadohealth.2009.09.009

Journal of Attention Disorders, Vol 19, No. 10 (October 2015): pg. 844-855. DOI. This article is @ SAGE Publications and permission has been granted for this version to appear in e-Publications@Marquette. SAGE Publications does not grant permission for this article to be further copied/distributed or hosted elsewhere without the express permission from SAGE Publications. 